\title{
Which Propaganda?
}

The librarian of the University of Maryland believes that as pressure groups multiply in number and intensity the problem of "which propaganda" shall be admitted to libraries becomes increasingly acute. Exclusion, education, and censorship fail to provide clear-cut solutions hence usefulness must of necessity be adopted as the guiding principle for admission.

$\mathrm{T}$ HE FIRST overt act of the Royal Air Force in the present European War, namely, the bombardment of German territory with leaflets rather than bombs, leads one to believe that the effectiveness of "paper-bullets" is now recognized as a major weapon of war. During the past few years we have undoubtedly witnessed their use in time of peace on a constantly increasing scale due to a variety of factors, not the least of which are the ever growing facilities for the communication of ideas. From all quarters, the "vested interests," labor, and proponents of various political concepts seek to influence thought and contribute drops to the shower of propaganda which drizzles upon the public mind. And now, the present European situation with its American repercussions will undoubtedly bring forth a new crop of materials as belligerents, isolationists, and interventionists seek to sway public opinion.

Of one fact we can be very sure. The propaganda of today and of the future will be far more subtle and insidious than heretofore, consequently more effective unless steps be taken to counteract its efficacy. The old stories of mutilated women and children, crucified soldiers, and human soap factories are apt to be taken with grains of salt in view of the excellent studies and consequent exposures of propaganda techniques during the last World War. Indeed, one of the most encouraging signs of the day in this connection is the awareness of the general public that propagandists are at work on a large scale. That a problem exists is evidenced by the number of articles and books on the subject written during the past few years. The Institute for Propaganda Analysis, founded in 1937 , is another sign of the growing interest, even the need, for more systematic study and effort to counteract the worst effects of propaganda. In our professional journals we find repeated evidence of awareness of the problem. The question facing librarianship iswhat course of action shall be adopted in handling the propaganda menace? Shall we withdraw into our ivory towers and let events take their course, as we have so often done in the past, putting implicit faith in the maxim "Let all sides be represented"? Or shall we-can we-formulate a policy which smacks of constructive action?

\section{Propaganda Types}

In attempting to pose various aspects of the question some consideration must be given to the nature and types of propaganda. Of many definitions the most apt 
seems to be one phrased by the late Calvin Coolidge, taken from Squires' recent article in the Library Journal. ${ }^{1}$ Coolidge said:

Propaganda seeks to present part of the facts, to distort their relations, and to prove conclusions which could not be drawn from a complete and candid survey of all the facts. Of real education and real information we cannot get too much; but of propaganda we cannot have too little.

The reason for using this definition in preference to several others is the distinction drawn between propaganda and education-a distinction which must be recognized in dealing with this problem. That we should have a formal definition of some kind for our own use is important ; otherwise we may simply fall into the habit of considering as propaganda anything with which we do not personally agree or which runs counter to the generally accepted ways and thinking of the dominant groups in society.

Furthermore in considering propaganda in the light of the definition given, or any other for that matter, it would seem that a distinction might well be made between "good," "harmful," and "innocuous," or relatively innocuous, material.

As far as "good" propaganda is concerned we usually call it "educating the public." We propagandize on behalf of libraries, the Red Cross, the Community Chest, and a dozen other projects, yet we never think of ourselves as being the villains of the piece. These causes are generally accepted as worth while today-but, how much of the attitude held toward them now can be attributed to propaganda in the past? We accept such propaganda today-do our bit to help these causes along-because they have attained a cer-

1 Squires, J. Duane. "Credulity or Skepticism." Library Journal 64:628. Sept. 1, 1939. tain position in our society. Would it be too much to say that in so doing we practice, by implication at least, a reverse censorship by elevating some propaganda to the level of education? However, the problem is not concerned primarily with this type but with the remaining two categories.

There is a certain religious group with headquarters in Zion, Ill. According to this sect the world is not round but flat. Presumably this group propagandizes to a certain extent but, to all appearances, such doctrine is harmless or relatively so. Ultimately, of course, any opinion such as this may be considered harmful in that it sets one group against another. Similarly in the case of anti-evolution. Harmless, except that the group sponsoring it may become strong enough to secure the passage of legislation affecting teaching in the schools, as was the case in Tennessee a few years ago. In contrast with this, however, we have "harmful" or dangerous propaganda, the doctrines of Communism. Fascism, and National Socialism, for instance, which, if successful, will result in radically altering the concept of the state and democracy which we presumably hold today. Propaganda of this type, setting forth a particular doctrine may make that doctrine a reality, whereas statements that the world is flat will not alter the shape of the globe no matter how many people believe it, unless one adopts the somewhat Pollyanna-ish attitude that thinking makes it so. Of course, there is always the possibility, as has been pointed out, that some seemingly innocuous doctrine might ultimately result in restrictions on religious liberty and academic freedom. For the present though, it would seem that this distinction might well stand as between the immediate and possible, and the ultimate 
though improbable, results of these two types of propaganda.

\section{Exclusion, Education, or Censorship?}

Policy in the past has been grounded principally on the classic attitude of having all sides represented subject to certain limitations with regard to good taste, style, and manner of presentation. That these limitations are apt to be ineffective is obvious in the light of the newer methods of propaganda. As propagandists become increasingly aware of the importance of format-as they already have to a certain extent-as they become increasingly subtle in their presentation of the facts and in choice of channels, these limitations tend to lose whatever effectiveness they may once have had. Hence it seems important, at this time, to pose various possibilities looking toward redefinition of policy by considering briefly the various means which might be adopted in handling the propaganda problem.

A drastic step would be to attempt to exclude all propaganda from library shelves. This, however, is neither practical nor wise. Such material, in the first place, has a degree of historical value if nothing else. The excellent studies of propaganda and propaganda techniques which are in existence today would not have been possible without the provision of a body of material for research. Second, such material has immediate value in certain instances. Several years ago one of the collegiate debate topics was on the Japanese-Manchukuo question. Those students who were to uphold the Japanese invasion of Manchukuo as justified would have been sorely pressed for material had it not been for the booklets setting forth the Japanese case. Furthermore, exclusion would be practical only for such ma- terial as came in the form of separates and this would not be complete by any means, for frequently articles appearing in reputable magazines are in reality propaganda. Short of removing the offending pages there is no way to prevent such material from entering libraries. From the standpoint of practicality then, exclusion is not the answer even if it were wise policy and this is seriously in doubt. As Doob points out modern society is badly perplexed with regard to the solution of certain problems which face this unbalanced world. As long as problems exist we shall have propaganda-on the part of those trying to bring about reforms and of those who are trying to prevent them. By and large, propaganda to be successful must be of the type which people will support. The efforts of the New York Society for the Suppression of Vice are increasingly less successful as America tends to outgrow this type of self-flagellation, whereas the American Association for Social Security is beginning to achieve its aim in a society now becoming ripe for old age pensions. $^{2}$ It is this latter statement which bears emphasis. Propaganda undoubtedly helped to bring about this "ripeness for old age pensions." By closing libraries to all propaganda we would stand for the status $q u o$ and commit librarianship, tacitly at least, to a policy of "no reforms."

A second possibility represents the tried and perhaps true method of education. Let us educate our students that they may be able to weigh the evidence and opposing arguments in a judicial manner; let them be taught to seek all the facts and not be satisfied with the glib distortions of propagandists. Obviously, most of this educative process would have to be done

2 Doob, Leonard, Propaganda, Its Psychology and Technique. Holt, I935, pp. 406.07. 
by the teaching staff of our institutions, as it is being done already to a certain extent. But how can librarians aid in this campaign of education? One means is to have the fundamental works for the study of propaganda available as well as the histories of propaganda which expose the fakes practised on a credulous public during the last World War in particular. The publications of the Institute for Propaganda Analysis should not only be available but should be publicized. But even beyond this point can anything be done to emphasize the fact that the printed word is by no means sacred-or truthful? Perhaps a note of warning could be placed on the cover or the title page indicating that the contents should not be taken too literally. This would mean a lot of work for already heavily burdened staffs but it should prove helpful. It has been reported to the writer that this is being done in some cases.

\section{Third Possible Course of Action}

A third possible course of action would be the establishment of censorship to eliminate the most harmful material. Here again certain technical difficulties would be encountered as in the first case but separates could be weeded out. Apart from the technical aspects what of the wisdom of censorship? Any mention of the word is apt to raise a tremendous hue and cry about the constitutional right of free speech and abandonment of the library's heritage of impartiality. Consider the following statement, however:

While the Library's Bill of Rights (A.L.A. Bulletin 33:5I, Jan. 1939) states that in no case shall selection of books and other reading matter for purchase from public funds "be based upon the race or nationality, political or religious views of the writers" and "as far as available material permits, all sides of controversial questions shall be represented equally in the selection of books on subjects about which differences of opinion exist" librarians must remember that they are, in troublous times like these, in a unique position to disseminate knowledge and truth. To conscientiously carry out their trust a certain degree of alertness, sensitivity to bias and the purely propagandistic, and honest evaluation must be practised in the selection and circulation of printed materials. ${ }^{3}$

This statement rings strangely familiar. How many times have we been reminded of our responsibility and unusual position to spread the light of truth? What better way is there of aiding truth than by suppressing untruth? As to our heritage of impartiality are we actually serving the best interests of civilization when, by maintaining strict impartiality we eventually aid, tacitly at least, in destroying that very ideal? In pre-Hitlerian days, in all probability, our German brethren maintained a policy of impartiality-of having all sides, including National Socialism, represented. By so doing German librarians passively assisted in spreading the Nazi doctrine. By standing for freedom of expression they assisted in destroying it for one of the first acts of the Hitler regime was to "coordinate" libraries. Presumably we are all committed to the democratic ideal although we may differ in definitions of the American way. Does the idea of impartiality and freedom of speech, however, create an obligation for us to nourish that which is inimical to the democratic ideal until the enemy grows strong enough to destroy all pretense of freedom of thought and expression? Critics will arise to question our

\footnotetext{
${ }^{3}$ Heaps, Willard A. "Books for the "Long and Calm View' on the Crisis, Its Background and Calm View' on the Crisis, Its Background and 34, Oct. I, 1939 .
} 
competence to act as arbiters of right and wrong were such a policy adopted. Similarly the analogy of fighting for democracy only to destroy it in the fighting therefor would be used against us but, even so, cannot censorship be justified by implication? Books are selected for libraries with a great deal of care and every attempt is made to eliminate, as far as possible, those which are not authoritative, accurate, or impartial. By what token should all kinds of material be placed in libraries because it comes for the most part in the form of donations? So much for three possible methods of handling propaganda ; namely, exclusion, education, or censorship.

\section{Desirability of Establishing Values}

It has already been stated that as long as problems remain to be solved in our society propaganda will exist. In a changing society values are bound to change. There can be no absolute truth and as a result there must be propaganda. The question is which propaganda shall we accept? The reasons for this question are many, but unfortunately there is no clearcut answer because there are no social values which we may automatically accept. The medical profession, motivated by a biological value that life is preferable to death, never hesitates to attempt the cure of a sick person. But what values are there which can scientifically describe the best form of government in the same way a scientist can describe the best conditions for performing a given experiment? There are none. The social values which exist are those set up by the people themselves. It is not too much to think, however, that some clarification of the issues which determine social values is possible. If leaders in all phases of human thought and activity should join in a concerted effort it should be possible to formulate a set of social values beneficial to mankind. ${ }^{4}$ As a contribution to our long sought after philosophy of librarianship let us take a stand looking toward the formation of such a group, aid in determining values, and then attempt to translate them into reality. Only by resorting to propaganda to cure the ills of the world can propaganda be eliminated. An idealistic program, to be sure, but not utterly impossible of achievement.

\section{What of the Present?}

In the meantime, what of the present? Obviously we cannot accept everythingwe do not accept everything sent to our libraries. But still "censorship" is scarcely even whispered. Much of the material is relegated to the wastebasket on grounds other than content, no doubt, which does relieve the charge of censorship somewhat. Concretely speaking, what treatment shall bc accorded propaganda in libraries considered strictly from the viewpoint of content and on the assumption that space is available and staff large enough to process every little pamphlet which comes to the library?

The primary purpose of the college library is to furnish material to support the courses of instruction; the university library adds the provision of research materials to its instructional function; and the great reference libraries emphasize the research activity almost exclusively. Books for these three related types of libraries are selected basically to perform these functions. Is there any reason why the same standard should not be applied to the treatment of propaganda? Admittedly this policy leaves much to the librarian's

- Doob. op, cit. pp. 4 Io ff. 
judgment but if he is competent to select he should also be granted competence to reject material. Although this solution provides no specific formula whereby propaganda can be automatically tested, admitted or rejected, it would seem that fundamentally usefulness could be accepted as the first principle for admission. With this as a guide all three types of propaganda ; namely, "good," "innocuous," and "harmful" would be admitted in proportion to their usefulness in any given type of library. Regardless of policy the first two types need cause little concern. As far as the third, or "harmful," type is concerned it would seem our function might go beyond education or censorship, even beyond any treatment which may be devised for the actual handling of this material.

\section{No Immediate Cause for Alarm}

It is still generally agreed that "it can't happen here." As long as this condition exists there is no particular cause for alarm over the subversive effect of propaganda in our college, university, and reference libraries for two reasons. First, we are dealing to a certain extent with an enlightened clientele and one which has been more or less exposed to some "education" with regard to propaganda. Second, propaganda to succeed must have a fertile ground. As long as we are a moderately prosperous, confident, and reasonably well satisfied people we are not apt to fall prey to political or economic "isms." So, it would seem that in troublous times like these it behooves us to look beyond the actual treatment accorded propaganda; to look, rather, toward the possibility of aiding in the solution of the problems which now give rise to propaganda, to be keenly aware of the changes taking place in our political, economic, and social life and, at the first sign of danger to the system which has given rise to libraries and freedom of thought and expression on an unprecedented scale we should be ready to adopt vigorous counter measures. Amidst all this we must remember that values change and we cannot put ourselves in the position of being unalterably opposed to change. All this will require a keen mind and a deep understanding of humanity, but the challenge and the prize are worthy.

\section{Reclassification of College and University Libraries}

(Continued from page ${ }_{16} 6_{4}$ )

\section{Libraries That Cooperated in the Study}

Brown University, Providence

Catholic University of America, Washington

Colby College, Waterville, Me.

College of Saint Catherine, Saint Paul

Cornell University, Ithaca, N.Y.

Harvard University, Cambridge, Mass.

Haverford College, Haverford, Pa.
Iowa State College, Ames

Johns Hopkins University, Baltimore

New York University, New York

Ohio State University, Columbus

Stanford University, Calif.

Swarthmore College, $\mathrm{Pa}$.

Temple University, Philadelphia

University of California, Berkeley

University of Cincinnati, Cincinnati

University of Michigan, Ann Arbor 